\title{
SIMULATION DER DYNAMIK DES RESSOURCENABBAUS UNTER BERÜCKSICHTIGUNG VON RECYCLINGPROZESSEN
}

\author{
Carsten Oder, Universität Karlsruhe \\ Hans-Dietrich Haasis, Universität Karlsruhe \\ Otto Rentz, Universität Karlsruhe
}

Der Abbau von Ressourcen, ihr Verbrauch und der Zuwachs der Abfalldeponierung werden in zunehmendem Maß zu einem Problem industrieller Staaten. Zur Lösung des Problems wird versucht, durch steigende Recyclingquoten den Ressourcenabbau zu verlangsamen. Ziel dieses Papers ist, das dynamische Verhalten dieses Prozesses zu erfassen und unter verschiedenen Annahmen zu simulieren. Zu diesem Zweck wird aus dem Wirkungsgefüge der Ressourcendynamik unter Berücksichtigung von Recycling das dynamische Verhalten in Form von Differentialgleichungen quantifiziert, in einem Strukturbild dargestellt und unter Variation der Recyclingquote simuliert. Das System ist dabei in zweifacher Weise negativ über den Preis, der für die Ressource zu zahlen ist, rückgekoppelt. Zum einen werden die externen Folgekosten der Abfalldeponierung internalisiert, zum anderen steigt mit zunehmendem Preis die Rentabilität von Recyclingverfahren, die jedoch mit steigender Recyclingquote energetisch aufwendiger und damit teurer werden. Die Recyclingquote wird so eine nichtlineare Funktion des Preises. Das dynamische Verhalten des Systems, insbesondere die zeitliche Entwicklung von Abfallmengen und Ressourcenvorrat, werden simuliert, graphisch dargestellt und interpretiert. Von besonderem Interesse sind dabei hohe Recyclingquoten (zwischen 90 und $99 \%$ ), wobei sich 'sc':on für Recyclingquoten von $95 \%$ ein rrastischer Abfall des Ressourcenbestandes ergibt, ciar sich aufgrund der Rückkopplung der internalisierten Deponierungskosten und damit zurückgehender Nachfrage einem von der Recyclingquote abhängigen stationären Wert annähert.

Als Erweiterung des Modells werden andere mögliche Internalisierungsstrategien untersucht, die beispielsweise die nichtlineare Problematik bei Kumulation eines bestimmten Abfallstoffes wiederspiegeln. Als Ergebnis ergibt sich hierbei, daß eine stärkere Berücksichtigung der Abfallproblematik durch nichtlineare Kosteninternalisierung zu einer früheren Stabilisierung des Ressourcenvorrats auf höherem Niveau führt. 